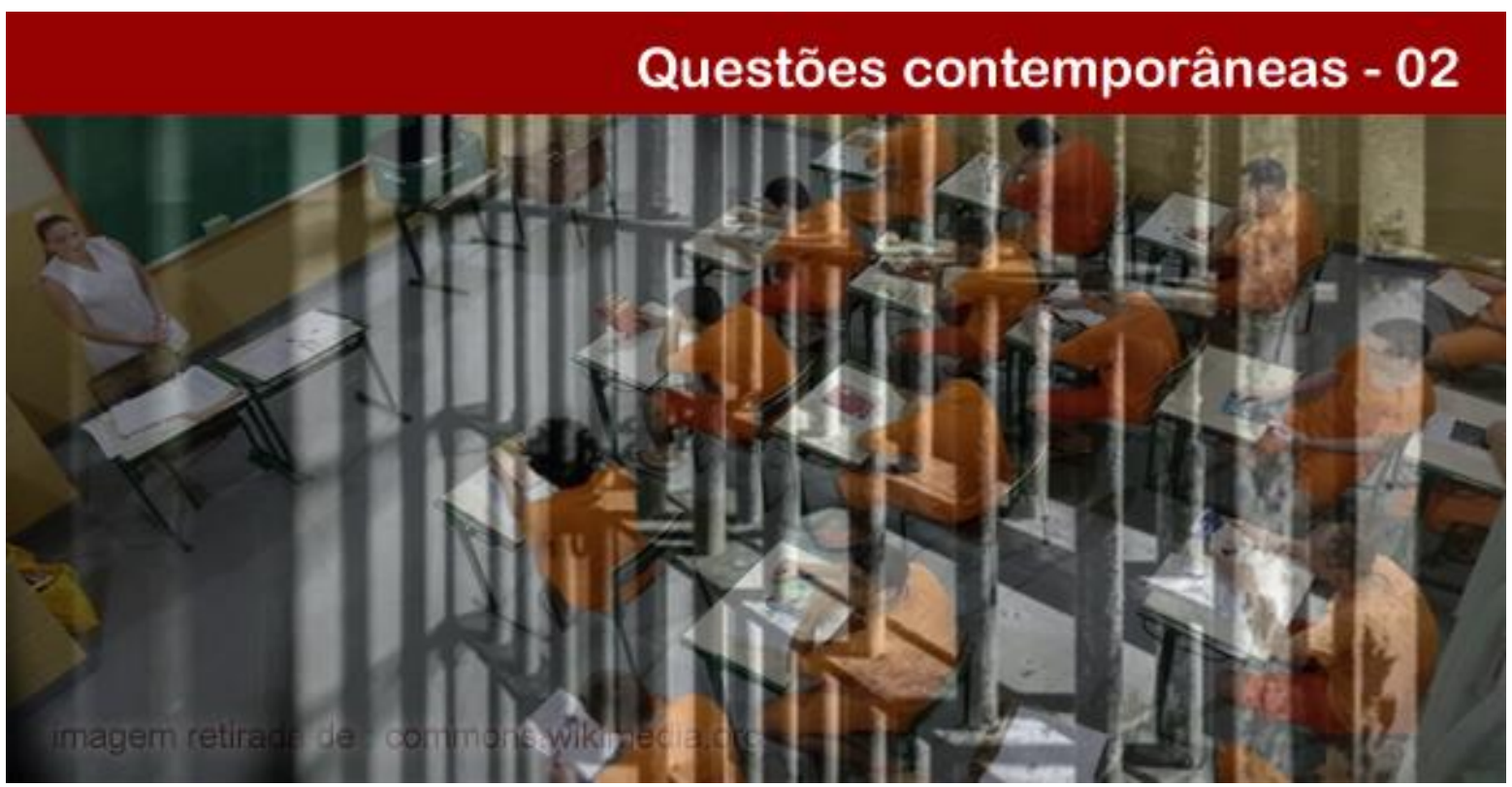

\title{
SIGNIFICADOS DA EDUCAÇÃO ESCOLAR PARA HOMENS PRIVADOS DE LIBERDADE
}

\section{Sonia De Lurdes Draguette Hillesheim}

Professora da Secretaria de Estado de Justiça e da Cidadania na Secretaria de Estado da Educação do Paraná. Mestre em Educação pela Universidade do Oeste Paulista. Graduada em Ciências Biológicas pela Universidade Estadual do Oeste do Paraná. E-mail: soniadraguette@ gmail.com.

\section{Camélia Santina Murgo}

Docente e Coordenadora do Programa de Pesquisa e Iniciação Científica do Curso de Psicologia da Universidade do Oeste Paulista. Pós-doutoramento em Avaliação Psicológica pela Universidade São Francisco. Doutora em Psicologia Ciência e Profissão e Mestre em Psicologia Escolar pela Pontifícia Universidade Católica de Campinas. Graduada e licenciada em Psicologia pela Universidade do Sagrado Coração. Líder do Grupo de pesquisa Formação de Professores e Construção dos Processos de Subjetividade (CNPq). E-mail: cameliaprof@gmail.com.

\section{Bárbara Cristina Soares Sena}

Mestranda pelo Programa de Pós-Graduação em Educação da Universidade do Oeste Paulista (UNOESTE). Graduada em Psicologia pela UNOESTE. E-mail: barbara_kristina08@hotmail.com.

Resumo: O objetivo proposto para esta pesquisa foi conhecer o que o educando privado de liberdade pensa a respeito da educação no cárcere, assim como verificar a importância atribuída por ele à escola. Para tanto, foram entrevistados oito participantes do sexo masculino, com idades entre vinte a quarenta anos, em situação de detenção em um presídio do estado do Paraná. Os resultados revelaram que não houve indicação de aspectos negativos quanto à educação ofertada no presídio. No sentido oposto do que se esperava, os educandos referemse à escola como um espaço formativo, acolhedor, que favorece a liberdade de expressão, o respeito e a formação de vínculos significativos com os professores. Acreditam na educação, mencionam metas e sonhos e mostraramse otimistas com relação ao seu futuro. Espera-se que o estudo colabore para a reflexão acerca de estratégias educativas que possam favorecer a sensibilização e a preparação de alunos privados de liberdade quanto à importância da educação na vida e no retorno à sociedade.

Palavras-chave: Educação de jovens e adultos. Privação de liberdade. Significados da educação.

\section{POLÊM!CA $\mid$ LABORE}

Polêmica - Revista Eletrônica da Uerj - Rua São Francisco Xavier, 524, $1^{\circ}$ andar bloco D, sl.1001 • Tels.: +55 21 2334-4088 / 4087 • http://www.e-publicacoes.uerj.br/index.php/polemica/index http://www.labore.uerj.br • laboreuerj@yahoo.com.br 


\title{
MEANINGS OF SCHOOL EDUCATION FOR PRIVATE FREEDOM MEN
}

\begin{abstract}
The objective of this research was to know what the learner thinks about the education in the jail, as well as to verify the importance attributed by him to the school. For that, eight male participants, aged between twenty and forty years, were interviewed in a prison in the state of Paraná. The results revealed that there was no indication of negative aspects regarding the education offered in the prison. In the opposite direction of what was expected, the students refer to the school as a formative, welcoming space that favors freedom of expression, respect and the formation of significant ties with teachers. They believe in education, mention goals and dreams, and show optimism about their future. It is hoped that the study will contribute to the reflection on educational strategies that may favor the sensitization and preparation of students deprived of their liberty regarding the importance of education in life and in the return to society.
\end{abstract}

Keywords: Youth and adult education. Deprivation of liberty. Meanings of education.

\section{Introdução}

Sabe-se que a educação brasileira, passou nos últimos anos, por mudanças expressivas. Premissas relacionadas a educação humanitária, que transforma e prepara para uma vida ativa e participativa na sociedade ganharam ênfase. Como representante desse modelo educacional humanitário e crítico, não poderia deixar de ser mencionado Paulo Freire, cujos ensinamentos perduram até hoje e fazem parte da realidade de muitas escolas por todo o mundo.

Compreende-se que o ponto principal da teoria do autor supracitado consiste no conceito de que o aluno deve aprender de uma maneira que possa desenvolver uma capacidade de relacionar os conteúdos problematizados em sala de aula com as vivências do mundo ao qual está inserido (FREIRE, 1996). Dessa forma, a verdadeira interpretação deste contexto precisa ser feita por meio da "leitura do mundo", ou seja, no primeiro momento o sujeito lê o mundo a sua volta e, posteriormente, passa à leitura das palavras, suscitando assim o seu processo de escolarização (FREIRE, 1989, p. 12).

No caso específico desta pesquisa, os ensinamentos postulados por Freire são de extrema importância, uma vez que os sujeitos que constituem o corpus do presente trabalho são privados de liberdade, fato que exige muito do professor, principalmente no que se refere ao respeito, ao diálogo, ao afeto e ao comprometimento em sala de aula. Neste contexto, cabe aos educadores sensibilizarem os seus educandos e apontar que a educação é, seguramente, a porta para a saída do mundo do crime, visto que é por meio dela que estes terão acesso ao mercado de trabalho e, futuramente, aos níveis mais elevados de educação. E quando se pensa na educação dialógica, entende-se que o diálogo não existe sem a esperança, pois esta encontra-se na base da inclusão dos sujeitos (FREIRE, 2016).

\section{POLÊM!CA $\mid$ LABORE}

Polêmica - Revista Eletrônica da Uerj - Rua São Francisco Xavier, 524, $1^{\circ}$ andar bloco D, sl.1001 • Tels.: +55 21 2334-4088 / 4087 • http://www.e-publicacoes.uerj.br/index.php/polemica/index http://www.labore.uerj.br • laboreuerj@yahoo.com.br 
Paulo Freire: diálogo e liberdade no ensino carcerário

Partindo do princípio posto pela teoria freiriana, o ensino deve preconizar a liberdade do aluno, independente da sua idade, haja vista que a educação é um dos pontos principais para que o ser humano consiga se libertar em todos os seus sentidos: social, político, econômico, entre outros. De acordo com o próprio Freire (2011), esta prática de liberdade é considerada um ato de conhecimento, sendo uma aproximação crítica do sujeito com a sua realidade e a educação pode contribuir para isto.

Nesse sentido, os educadores devem, para além dos conteúdos necessários e fundamentais a serem ensinados no ambiente escolar, instigar os educandos a pensar, refletir, criticar e transformar o ambiente em que estão inseridos (FREIRE, 2016). No ambiente da sala de aula, portanto, é fundamental que os educadores mostrem os inúmeros benefícios que a educação transformadora e libertadora possibilita, levando o educando a se reconhecer como sujeito da realidade histórica na qual se encontra inserido, humanizando-se e lutando contra a alienação imposta pela classe dominante através da violência e da opressão (BAUER, 2008).

E, ao encontro dessa questão, o diálogo é outro ponto imprescindível no ambiente escolar, tendo em vista que é por meio dele que o educador conseguirá cativar os seus educandos e mostrá-los os melhores caminhos a serem percorridos. Não há como ensinar sem que haja o respeito, o carinho e o diálogo na sala de aula, pois essa é a chave para a educação que liberta, que transforma, que prepara para o mundo. Portanto, segundo Freire (1996), o diálogo somente existe se houver amor pela humanidade, visto que este possibilita compreender o mundo a partir da criação e da recriação; sendo assim, o amor é fundamentado no diálogo e é o próprio ato de dialogar.

Freire (1996) afirma que os homens que refletem e posicionam-se no meio em que estão inseridos em um movimento dinâmico, dialético, entre o fazer e o pensar sobre o que fazer, são tidos como seres que transformam e conhecem o mundo por meio da sua ação e da sua prática. Assim, a educação para todos, especialmente para aqueles que estão privados de liberdade, pelos quais particularmente se interesse este estudo, precisa preconizar o desenvolvimento da consciência crítica e reflexiva em relação aos fatos do cotidiano e do meio em que estão inseridos, devendo isso ser compromisso de todos aqueles que estão envolvidos com tal educação. Para tanto, se faz necessária a conscientização histórica dos sujeitos, que ocorre com

\section{POLÊM!CA $\mid$ LABORE}

Polêmica - Revista Eletrônica da Uerj - Rua São Francisco Xavier, 524, $1^{\circ}$ andar bloco D, sl.1001 • Tels.: +55 21 2334-4088 / 4087 • http://www.e-publicacoes.uerj.br/index.php/polemica/index http://www.labore.uerj.br • laboreuerj@yahoo.com.br 
a inserção crítica na história, fazendo com que estes assumam o papel de fazer e refazer o mundo (FREIRE, 2001).

$\mathrm{O}$ ato educativo, portanto, deve ser significativo, possibilitando que os educandos relacionem os conteúdos com os seus problemas cotidianos e tenham condições de alterá-los sempre que for possível e necessário. Nessa concepção, para a educação ser considerada válida, deve-se analisar as condições em que o sujeito vive, no seu contexto exato (FREIRE, 2011). Assim sendo, a partir dessa perspectiva e ao pensar sobre a educação dentro de contextos específicos, como no sistema prisional, pode-se afirmar que existindo uma comunicação entre o presídio e a instituição que oferta o Ensino para Jovens e Adultos (EJA), é mais provável que os objetivos sejam atingidos com sucesso junto aos educandos em detenção.

Ao analisar a educação neste cenário também é preciso levar em consideração a estruturação do sistema carcerário brasileiro, que vive um caos. As dificuldades vão desde a superlotação das celas até a proliferação de doenças e práticas de violências e agressões, fazendo com que a maioria dos apenados, ao saírem em liberdade retornam para o mundo do crime e em decorrência disso retornam aos presídios dentro de pouco tempo, deixando evidente que o sistema carcerário não cumpriu sua função, isto é, ressocializar o preso (PEREIRA, 2017). Diante deste contexto, a educação tem um papel essencial por se configurar como um fator favorável e que, em meio a tantas adversidades, se torna um dos poucos meios efetivos de ressocialização e inclusão social do detento (JULIÃO, 2010).

\section{Educação prisional como prática ressocializadora}

Durante anos, o planejamento e a estruturação da educação em presídios tem fomentado intensas discussões na sociedade e nos órgãos governamentais, em particular no Ministério da Educação e no Ministério da Justiça, que buscam tornar o sistema prisional brasileiro mais humano, garantindo o direito à educação a todos os privados de liberdade. Isso, de alguma forma, traz implícito o reconhecimento de que a educação contribui, positivamente, para a reintegração social da pessoa presa, promovendo-a cognitiva e socialmente (PEREIRA, 2018).

Neste processo de institucionalização da educação no espaço dos presídios, o Conselho Nacional de Justiça (CNJ) baixou a Recomendação 44/2014, dispondo sobre o oferecimento de atividades educacionais complementares para efeito de remição da pena e estabelecendo critérios para validação dessas atividades (BRASIL, 2014). Além disto, também foi lançado o

\section{POLÊM!CA $\mid$ LABORE}

Polêmica - Revista Eletrônica da Uerj - Rua São Francisco Xavier, 524, $1^{\circ}$ andar bloco D, sl.1001 • Tels.: +55 21 2334-4088 / 4087 • http://www.e-publicacoes.uerj.br/index.php/polemica/index http://www.labore.uerj.br • laboreuerj@yahoo.com.br 
Decreto Presidencial n ${ }^{\circ}$ 7626/2011, que instituiu o Plano Estratégico de Educação no âmbito do Sistema Prisional (PEESP). Tal decreto foi criado com o objetivo de ampliar as matrículas e de qualificar a oferta de educação nas prisões, incentivando assim a elaboração de Planos Estaduais de Educação para o Sistema Prisional (BRASIL, 2011).

Visando esta articulação, o Ministério da Justiça e o Ministério da Educação realizaram, no ano de 2013, o $4^{\circ}$ Seminário Nacional pela Educação nas Prisões, cujo objetivo principal foi o de auxiliar os Estados na elaboração destes planos, estabelecendo que os mesmos deveriam ser elaborados de forma conjunta entre a Secretaria de Estado da Educação e a Secretaria de Administração Penitenciária, com a participação ampla dos segmentos sociais envolvidos com a temática. O seminário também auxiliou na orientação dos profissionais responsáveis pela elaboração dos projetos e na efetivação da política de remição da pena por meio da educação, além de proporcionar o compartilhamento de experiências inovadoras que estão sendo desenvolvidas na área (UNESCO, 2006).

A educação no sistema prisional, considerada como prática social, é geradora de interações entre os sujeitos, promovendo situações que contribuem para a melhoria da qualidade de vida e, ainda, pode restaurar e valorizar as identidades e culturas marginalizadas, ocasionando o desenvolvimento de uma rede afetiva que auxilia a (re) conquista da cidadania (ONOFRE; JULIÃO, 2013). Dessa forma, para que a reinserção do detento se torne viável, de acordo com Hora e Gomes (2007), é preciso se pensar na educação como estratégia para que seus objetivos sejam alcançados na prática, e assim atingir a sua realização efetiva por meio do currículo elaborado e praticado nos presídios.

Nesse sentido, "é necessário educar todo o sistema prisional de maneira plena para que seja possível haver uma educação ressocializadora dentro das prisões, executando, deste modo, os objetivos sociais em relação aos detentos de ambos os sexos” (PEREIRA, 2011, p. 48). Isso posto, buscou-se, no presente estudo, analisar a maneira com que aprisionados significam a escola na situação de privação de liberdade em que se encontram. Destaca-se também que os resultados das verbalizações dos aprisionados sobre o significado que atribuem à escola na unidade prisional onde têm vivido serão discutidos à luz da perspectiva e dos ensinamentos de Paulo Freire e de pesquisas realizadas no mesmo segmento.

\section{POLÊM!CA $\mid$ LABORE}

Polêmica - Revista Eletrônica da Uerj - Rua São Francisco Xavier, 524, $1^{\circ}$ andar bloco D, sl.1001 • Tels.: +55 21 2334-4088 / 4087 • http://www.e-publicacoes.uerj.br/index.php/polemica/index http://www.labore.uerj.br • laboreuerj@yahoo.com.br 


\section{Método}

Trata-se de um estudo na modalidade exploratório-descritivo de abordagem qualitativa, e com temporalidade classificada como transversal. A abordagem adotada permitiu compreender o fenômeno a partir da perspectiva dos participantes, possibilitando, assim, analisar o significado da educação no cárcere na visão dos próprios detentos. Por fim, destacase ainda que foi realizado um levantamento bibliográfico para identificar pesquisas feitas no mesmo contexto e com base na mesma linha teórica para associações e discussões com os resultados encontrados.

Caracterização dos participantes e do contexto da realização do estudo

A amostra foi composta por oito detentos, com idade entre 22 e 40 anos, de uma penitenciária masculina no Estado do Paraná. O critério para a seleção foi estar frequentando a escola dentro do sistema prisional e demonstrar interesse em participar da pesquisa. Sendo assim, dos participantes selecionados, um estava cursando o Ensino Fundamental fase II da EJA, que no ensino regular corresponde do quinto ao nono ano; e sete cursavam o Ensino Médio.

Sobre o contexto de realização do estudo, cabe esclarecer que a normatização do atendimento educacional no Sistema Penitenciário do Paraná ocorre por meio das Diretrizes Nacionais para a Oferta da Educação em Estabelecimentos Penais aprovadas pela Resolução n 3, de 11 de março de 2009, do Conselho Nacional de Política Criminal e Penitenciária (CNPCP) (BRASIL, 2009).

\section{$\underline{\text { Instrumento }}$}

Inicialmente, foi aplicado um questionário (Anexo I) composto de 37 questões para identificar o perfil socioeconômico-e educacional dos educandos privados de liberdade. E posteriormente foi utilizado um roteiro de entrevista semiestruturado, adaptado do estudo de Araújo (2005). A entrevista foi constituída por 21 perguntas abertas que buscaram identificar os significados e a relevância do processo escolar no sistema prisional.

\section{POLÊM!CA $\mid$ LABORE}




\section{Procedimentos e análise dos dados}

O questionário e a entrevista foram realizados na sala de aula da penitenciária, em dias e horários previamente agendados, sendo o tempo médio de duração de, aproximadamente, 50 minutos para cada participante.

A análise dos dados foi feita por meio da técnica de Análise de Conteúdo (BARDIN, 2011), que é compreendida como um procedimento de desmembramento dos dados em unidades ou categorias. A categorização, conforme define Bardin (2011), é uma forma de classificação dos elementos constitutivos de um conjunto, por diferenciação e, posteriormente, por um reagrupamento coerente de núcleos semânticos associados à problemática central do estudo.

Os resultados encontrados foram discutidos à luz da perspectiva e dos ensinamentos de Freire e de pesquisas anteriores.

\section{Resultados e discussão}

Os resultados foram divididos em duas seções, sendo que na primeira é feita uma descrição da trajetória de escolarização dos participantes, e na segunda seção são apresentadas, através de blocos temáticos, as verbalizações dos aprisionados sobre o significado que atribuem à escola na unidade prisional que têm vivido.

\section{$\underline{\text { Seção } 1-\text { As trajetórias dos participantes }}$}

Como apontado, os educandos do sistema prisional responderam um questionário sobre o perfil socioeconômico e educacional, que possibilitou, primeiramente, a identificação de alguns dados significativos para compreender quem são os sujeitos participantes. Os resultados apontaram que em média $62,5 \%$ dos entrevistados são réus primários, com a pena média de condenação dos oito participantes em torno de dezenove anos e cinco meses, sendo que o tempo de pena cumprida por eles, até o momento em que a pesquisa foi realizada, era, em média, de três anos.

Em relação ao nível educacional familiar, quando indagados sobre o grau de escolaridade dos pais, indicaram que em relação às mães, três delas cursaram somente o Ensino Fundamental $\left(1^{\circ}\right.$ ao $9^{\circ}$ ano), duas concluíram o Ensino Médio, duas nunca estudaram e um dos entrevistados não soube responder qual o grau de estudo dos pais. Quanto aos pais, dos sete que

\section{POLÊM!CA $\mid$ LABORE}


responderam, dois não estudaram, dois cursaram somente o Ensino Fundamental (até $4^{\circ}$ ano e o outro até o $8^{\circ}$ ano, respectivamente) e três cursaram o Ensino Médio, mas somente um conseguiu concluí-lo. Em relação aos motivos da evasão escolar dos pais, três não responderam e os demais alegaram que os pais constituíram família e necessitavam trabalhar para sustentálas.

Sobre a própria escolarização, com exceção de dois dos participantes, todos alegaram ser a necessidade de trabalhar o motivo para interrupção dos estudos. Dos que alegaram motivos diferentes, um apontou como causa da desistência a influência dos amigos e o uso de drogas, e o outro entrevistado morava na rua desde os oito anos de idade, alegando não ter ninguém e, por esse motivo, nunca frequentou uma sala de aula no período em que estava em liberdade. Os relatos vão de encontro com os achados no estudo de Resende (2012), realizado numa penitenciária com 28 presos, no qual os detentos também indicaram que os principais motivos da interrupção dos estudos foram as drogas, além da necessidade de trabalhar para seu sustento ou da família e, por fim, a detenção.

Os entrevistados também foram indagados sobre a ocupação profissional antes da detenção. Apenas um, dos oito participantes, afirmou não estar exercendo atividade profissional na época da detenção. Dos outros, um era agricultor, um comerciante, um vendedor, um operador de máquinas de impressão, um jardineiro, um mecânico automotivo e o último trabalhava em uma livraria. Quanto à ocupação dentro do presídio, todos estudam e trabalham e três deles, além de trabalhar e estudar, também frequentam as aulas de músicas.

\section{Seção 2 - Os significados da escola}

As respostas do roteiro de entrevistas foram divididas em seis blocos temáticos, a saber: dificuldades e motivações no percurso escolar, metodologias de ensino sob o olhar do preso, relações interpessoais no dia a dia da escola, significado e importância da educação, propostas para melhoria da educação prisional e uma visão sobre esperança, ética e a beleza das coisas.

\section{Dificuldades e motivações no percurso escolar}

A abordagem desse tema foi referente às dificuldades encontradas na escola e os motivos pelos quais os participantes retornaram ao estudo dentro da unidade prisional. Nesse sentido, os entrevistados identificaram como obstáculos principais para a desistência escolar o

\section{POLÊM!CA $\mid$ LABORE}

Polêmica - Revista Eletrônica da Uerj - Rua São Francisco Xavier, 524, $1^{\circ}$ andar 
cansaço acarretado pela dupla jornada de trabalho e estudo e também as dificuldades de aprendizagem, sendo que um deles relatou possuir dislexia. Outro detendo relatou nunca ter frequentado uma sala de aula quando estava em liberdade, mas estuda no presídio e tem muita dificuldade de aprendizagem, a qual atribui ao uso de drogas utilizadas antes da detenção e que teria deixado sequelas que refletem na atual vivência escolar. Seguem alguns dos relatos que descrevem as dificuldades apontadas:

[...] cansava muito, trabalhava e estudava. A noite não conseguia estudar, porque tinha que acordar cedo para trabalhar.

Não estudei na rua, aqui na cadeia tive muita dificuldade por que usei muita droga. [...] sempre quis estudar, aprender escrever cartas e ler livros, com 23 anos não sabia ler e nem escrever, passava muita vergonha, tinha que pedir para as pessoas ler as placas de ônibus, só estudei em unidade prisional, a melhor oportunidade tive aqui no presídio.

Leite (2009) realizou uma pesquisa semelhante para compreender os motivos que levam os sentenciados a retornarem para a escola dentro das unidades prisionais. Percebeu-se que os detentos haviam motivos variados, como, por exemplo, passar o tempo, aprender algo novo e, ainda, a compreensão de que a escola era uma chance de conviver socialmente sem reincidir no crime e que, ao frequentá-la, reduzia-se a censura sofrida. Para o autor, não houve indícios de pontos negativos nesse retorno; o que se percebeu foram seres humanos que encontraram na educação um ambiente em que não são somente delinquentes, apesar de serem sentenciados e estarem pagando suas penas em locais propícios à exclusão.

Assim, as respostas dos participantes do presente estudo também demonstram diferentes interesses pela educação, tais como terminar o Ensino Médio, ingressar em uma faculdade, ter melhor oportunidade de emprego e remição de pena. Além disso, os educandos falaram sobre a importância de obter novos conhecimentos e reflexões sobre o mundo.

Portanto, compreende-se com os relatos que a educação deve ser promovida para auxiliar na recuperação da autoestima e, posteriormente, na reinserção do sujeito na sociedade. Assim como deve favorecer a realização pessoal, a profissionalização e o exercício da cidadania (TEIXEIRA, 2007).

\section{Metodologias de ensino sob o olhar do preso}

Esta unidade temática abordou o interesse que os educandos privados de liberdade demonstram pelos conteúdos, as formas de trabalho desenvolvidas na sala de aula, a dedicação

\section{POLÊM!CA $\mid$ LABORE}

Polêmica - Revista Eletrônica da Uerj - Rua São Francisco Xavier, 524, $1^{\circ}$ andar bloco D, sl.1001 • Tels.: +55 21 2334-4088 / 4087 • http://www.e-publicacoes.uerj.br/index.php/polemica/index http://www.labore.uerj.br • laboreuerj@yahoo.com.br 
em aprofundar os conteúdos nas celas, bem como a valorização das experiências trazidas por eles. Os educandos relatam e apontam suas visões em relação a maneira com que os conteúdos são trabalhados na escola prisional, como nas falas abaixo:

\footnotetext{
O conteúdo é bem explicado, bem conversado. [...] às vezes na sala de aula normal, na rua, não é tão bem explicado como aqui.

Os professores passam os conteúdos de uma forma que a gente consegue entender, e valorizam o conhecimento que a gente tem sobre o conteúdo que tá passando e é uma forma que ele tem de testar nossos conhecimentos.

[...] o professor explica bem, de várias formas e muitas vezes no debate, liga o assunto [conteúdo] com o dia a dia. Ouve, debate e valoriza nossa experiência.
}

A partir das verbalizações, os participantes destacaram que suas experiências pessoais são levadas à sala de aula e valorizadas por seus professores, acarretando, em várias aulas, debates significativos. De acordo com a teoria freiriana, o educador não deve restringir seu papel ao de falar aos educandos somente sobre sua visão ou lhes impondo seus conceitos, mas deve propiciar o diálogo com eles sobre a sua visão e a dele (SAUL; SAUL, 2016). Compreende-se que a tarefa do educador não é apenas falar e dissertar, mas também problematizar a realidade concreta dos educandos (FREIRE, 2011). Indo de encontro com esta visão, os participantes do presente estudo apontaram que ocorre no ambiente educativo do sistema penitenciário a vivência de diálogo e reflexão entre eles e os educadores.

Apesar disso, os educandos manifestam que, apesar dos professores se dedicarem na apresentação e discussão dos conteúdos, o fato de cada aluno estar matriculado em uma série, de forma individualizada, mas ter as aulas juntos na mesma sala, faz com que o desenvolvimento das aulas fique prejudicado. Abaixo, seguem as falas dos participantes que demonstram este aspecto:

O professor trabalha com muitos conteúdos diferentes em uma sala só, devido ao atendimento individual, e isso trava o professor, mas aqui não pode ser outro sistema, por causa do trabalho.

[...] é diferente do que ocorria na rua, aqui [no sistema prisional], o sistema EJA trabalha com o aluno de forma individual, eu acho que é pouca dedicação para o aluno, limita o professor, mas não dá pra ser de outro jeito.

Em suma, quanto ao desenvolvimento das aulas pelos professores, as respostas dos participantes demonstram que são bem ministradas e que há entendimento dos conteúdos.

\section{POLÊM!CA $\mid$ LABORE}

Polêmica - Revista Eletrônica da Uerj - Rua São Francisco Xavier, 524, $1^{\circ}$ andar bloco D, sl.1001 • Tels.: +55 21 2334-4088 / 4087 • http://www.e-publicacoes.uerj.br/index.php/polemica/index http://www.labore.uerj.br • laboreuerj@yahoo.com.br 
Porém, reclamam do sistema de matrícula ser individual e não por turma e, com isto, em uma mesma sala de aula os educandos têm aulas sobre conteúdos diferentes. Esse fato, segundo alguns participantes, dificulta e limita o trabalho do professor. Mas, ainda com as dificuldades, os educandos concordam que o sistema normal de matrículas, como é feito nas escolas regulares, não é viável dentro do presídio devido à grande rotatividade dos detentos nos períodos de aula, em virtude dos setores de trabalho.

\section{Relações interpessoais no dia a dia da escola}

A discussão subsequente se faz a respeito dos relacionamentos estabelecidos dentro do presídio, principalmente com os professores e os demais detentos. Notou-se que a maioria dos participantes apontou que as relações se estabelecem com respeito e colaboração e sobre como lidam com o preconceito existente em relação a condição que os levaram à detenção e que deve ser evitado no ambiente escolar, como fica explicitado nas falas a seguir:

\footnotetext{
O relacionamento entre os presos e o professor é de respeito. [...] há colaboração; apesar de estar preso é como se fosse um colégio da rua. [...] E na sala de aula procurase evitar esse tipo de coisa [preconceito] mesmo com os artigos [crimes] mais complicados dos outros presos.
}

Relacionamento de respeito com os professores e os colegas, porém não converso e não aceito o crime do artigo 213 [estupro]. Colaboramos com os professores com silêncio, participando das aulas e auxiliando com o material.

O relacionamento é bom. A professora escreveu no meu caderno: “A educação muda o homem e o homem muda o mundo, espero que você seja uma dessas pessoas"; isso me fez refletir. [...] existe auxílio nas atividades e com os materiais. Não tenho percebido preconceito.

Ao encontro dessa questão, Mól (2013) fez um estudo em Minas Gerais sobre a educação para adultos privados de liberdade, e em sua pesquisa com os educadores, percebeu que eles buscam tornar o ambiente escolar humano e que, por mais que possam estar inseguros, procuram não demonstrar esse sentimento, transmitindo mensagens de esperança, de paz e de amizade aos alunos privados de liberdade. Como se percebe, os entrevistados relatam que, apesar das dificuldades, a tentativa é de sempre manter o respeito e a colaboração.

Na perspectiva da teoria freiriana, esta colaboração em sala de aula ocorre a partir do diálogo e da comunicação efetiva entre educador e educando; desta forma, vão sendo construídos caminhos para uma participação responsável por parte de todos os envolvidos no

\section{POLÊM!CA $\mid$ LABORE}

Polêmica - Revista Eletrônica da Uerj - Rua São Francisco Xavier, 524, $1^{\circ}$ andar bloco D, sl.1001 • Tels.: +55 21 2334-4088 / 4087 • http://www.e-publicacoes.uerj.br/index.php/polemica/index http://www.labore.uerj.br • laboreuerj@yahoo.com.br 
ato educativo (FREIRE, 1996). O diálogo sugere o reconhecimento do outro, assim como citado pelos entrevistados deste estudo.

\section{Significado e importância da Educação}

Alguns autores (SOARES, 2015; SOARES; VIANA, 2017) apontam que, apesar de se considerar a Educação como um benefício e direito aos presidiários, muitas vezes ela não é entendida como tal por uma parcela da sociedade. Mesmo com a perda dos direitos civis e políticos, em momento algum se deve suspender os direitos constituídos por lei aos sujeitos, tais como respeito, dignidade, integridade física, psicológica e moral, e ainda o desenvolvimento pessoal e social (SOARES, 2015). A educação tem a capacidade de desenvolver potencialidades, colaborando de forma favorável para melhorar a qualidade de vida não somente dentro do sistema prisional, mas também para um retorno de maior qualidade ao contexto social.

Neste momento, apresenta-se, então, a visão dos detentos sobre a importância da Educação no presídio e se esta trouxe novos conhecimentos ou acrescentou algo que o fez refletir sobre sua vida.

Sem estudo não se consegue um serviço melhor, o estudo serve pra ter um futuro melhor. [Serve] para a pessoa ter uma boa conduta, saber se portar, aprender a respeitar para ser respeitado. As aulas sempre fazem a gente refletir.

Para mim a "educação muda o homem e o homem muda o mundo", "Paulo Freire". A Educação agrega e acrescenta, quanto mais educação, mais polida, intelectual e sábia a pessoa se torna. [...] a professora, escreveu no meu caderno: "A educação muda o homem e o homem muda o mundo, espero que você seja uma dessas pessoas"; isso me fez refletir.

Os detentos destacam, principalmente, o interesse pela educação para uma possível melhoria da condição de vida após o cumprimento da pena. Muitos consideram o que aprendem na escola prisional como um caminho para a ressocialização e como uma forma de obter futuramente condições pessoais e sociais melhores. Percebe-se que o contexto educacional no Brasil tende a priorizar o ensino bancário no lugar de uma educação problematizadora (FREIRE, 2011), e tendo em vista o cenário prisional, torna-se ainda mais difícil trabalhar com o ensino na busca de formação de indivíduos reflexivos e críticos (SOARES; VIANA, 2017).

É preciso levar em consideração esse interesse dos educandos prisionais em considerar a educação como possibilidade e torná-los críticos para quando reinseridos no contexto social,

\section{POLÊM!CA $\mid$ LABORE}

Polêmica - Revista Eletrônica da Uerj - Rua São Francisco Xavier, 524, $1^{\circ}$ andar bloco D, sl.1001 • Tels.: +55 21 2334-4088 / 4087 • http://www.e-publicacoes.uerj.br/index.php/polemica/index http://www.labore.uerj.br • laboreuerj@yahoo.com.br 
de modo que encontrem novos meios de se integrarem. Sousa (2013) ressalta que essa esperança é praticamente o único recurso que está ao alcance do detento, e torna-se uma saída para a morte existencial cotidiana que encontram na prisão.

Outros participantes também verbalizaram que a educação dentro do presídio é um fator importante para quando estiverem fora do sistema, como um caminho de possibilidades novas.

O que eu aprendo, posso passar para os filhos e outras pessoas, acrescenta conhecimento, pra poder ter família mais estruturada e um emprego melhor. Penso em sair daqui e ser melhor; teve alguns filmes que assisti na escola, me emocionei e me fez pensar em dar mais valor à vida.

[A educação] é uma forma de estar se ressocializando para sair lá fora e por meio do estudo ter uma oportunidade melhor e conseguir também um trabalho melhor. Se tivermos um grau superior de educação, isso nos fará ter atitudes diferentes.

Os participantes revelaram que a educação faz a diferença, uma vez que é por meio dela que se tem acesso a diferentes culturas, a novas possibilidades de um emprego melhor e de se tornarem, como foi dito, um "cidadão de bem" após a saída da detenção. Em seu estudo sobre a educação dentro do sistema penitenciário, Araújo (2005) ressalta que para que exista a libertação do homem visando o convívio social, é indispensável que a educação prisional seja fundamentada na integração entre "os saberes: ser, conviver, fazer e conhecer; que envolva todos os segmentos da unidade prisional e que tenha o apoio da sociedade" (ARAÚJO, 2005, p. 204).

Oliveira (2012) também desenvolveu uma pesquisa que teve o objetivo de fomentar uma reflexão crítica a respeito da educação prisional. O estudo foi desenvolvido em uma penitenciária do estado de Minas Gerais e identificou-se que a educação indica uma perspectiva transformadora da realidade vivida que ultrapassa a esfera jurídica, caracterizando uma relação entre o estudo e a possibilidade de conquistar benefícios, tais como: "ocupar o tempo" e ter "remição de pena". A pesquisa mostrou, ainda, que a escolarização favorece o acesso à profissão e ao universo do trabalho, bem como contribui para as elevações pessoal e social em relação ao dano causado pela prisão, facilitando a ressocialização após o cumprimento da pena.

A teoria freiriana vem dizer, portanto, que é preciso repensar a educação para que ela possa ser o alicerce na formação de seres humanos que possam ir além, tornando-se atuantes e aptos para a convivência em sociedade (FREIRE, 2011). Nesta perspectiva, deve-se pensar no ato educativo dentro do sistema prisional como um facilitador de novas formações de seus

\section{POLÊM!CA $\mid$ LABORE}

Polêmica - Revista Eletrônica da Uerj - Rua São Francisco Xavier, 524, $1^{\circ}$ andar bloco D, sl.1001 • Tels.: +55 21 2334-4088 / 4087 • http://www.e-publicacoes.uerj.br/index.php/polemica/index http://www.labore.uerj.br • laboreuerj@yahoo.com.br 
detentos, visto que estes se encontrarão mais preparados para a reinserção social após o cumprimento da pena.

\section{Propostas para melhoria da educação prisional}

Aqui, serão abordados os questionamentos e sugestões dos participantes em relação à unidade prisional em que se encontram e de que forma seria possível que a educação dentro da penitenciária se fizesse mais efetiva e os auxiliasse para o retorno à sociedade. Seguem os relatos dos detentos sobre este tema:

Poderia dar uma condição melhor para o professor na sala de aula, liberação de determinados materiais, como computador, TV, vídeo e outros que a escola é carente. [...] a unidade está auxiliando, os professores são ótimos e pelas atividades que a gente faz aqui, em outros lugares o preso tem que ficar só na cela sem fazer nada.

[...] sair todos os dias para estudar, por que muitas vezes não saímos para estudar por falta de agentes penitenciários. [...] trabalhei na rua e nessa época não consegui estudar, seria importante se os presos que trabalham fora pudessem estudar também, no final da tarde ou na cela. A escola é muito importante auxilia muito, mas a unidade em si não auxilia [...].

Sobre as sugestões, de um modo geral os alunos privados de liberdade fizeram muitas reivindicações, sugerindo a necessidade de mais recursos humanos, especialmente mais agentes para facilitar as movimentações dos detentos para a escola e para os canteiros de trabalho, visto que, muitas vezes, os detentos não saem das celas por falta de funcionários que os acompanhem. Evidencia-se com os relatos a precarização das penitenciárias em relação aos recursos humanos, desencadeando várias restrições dentro do ambiente prisional, afetando, concomitantemente, a escola prisional.

Em seu estudo, Silva e Moreira (2011) ressaltam que o sistema prisional precisa ser transformado em um poderoso espaço pedagógico e, para tanto, é preciso criar mecanismos para que os agentes penitenciários sejam parceiros da escola e, mais ainda, que sejam também eles educadores, proporcionando que as relações dentro dos presídios sejam predominantemente pedagógicas, para que os detentos possam ser verdadeiramente (re)educados. Pereira (2011), por sua vez, afirma que é necessário educar todo o sistema prisional de maneira plena, para que seja possível haver uma educação ressocializadora dentro das prisões, executando, desse modo, os objetivos sociais em relação aos detentos.

\section{POLÊM!CA $\mid$ LABORE}

Polêmica - Revista Eletrônica da Uerj - Rua São Francisco Xavier, 524, $1^{\circ}$ andar bloco D, sl.1001 • Tels.: +55 21 2334-4088 / 4087 • http://www.e-publicacoes.uerj.br/index.php/polemica/index http://www.labore.uerj.br • laboreuerj@yahoo.com.br 


\section{Sobre esperança, ética e a beleza das coisas}

Foi solicitado durante a investigação que os participantes exprimissem o que pensam sobre ter esperança quanto ao futuro e também sobre o que ainda conseguem perceber de bom na situação e no ambiente em que se encontram. Abaixo ficam explicitadas nas falas dos detentos o que esperam levar consigo quando voltarem a conviver em sociedade.

A palavra esperança representa tudo, sair logo daqui, pagar a pena, sair de cabeça erguida. [...] tem pessoas aqui dentro que são muito pra baixo e não conseguem ver beleza em nada. A escola auxilia, os professores estão sempre ajudando os presos a levantar o ego.

Consigo ver beleza, mas nos presos só vejo maldade, sempre me julgando porque sou usuário de drogas. As pessoas aqui que me querem bem são os agentes, setor de enfermagem. [...] o que sou devo à escola, só estudei aqui dentro e estou terminando o ensino médio.

A maior parte dos entrevistados mencionou a escola e os professores como motivadores, que os incentivam a pensar no fim da condenação com esperança de encontrar novos caminhos. Os apontamentos vão de encontro com o sentido de escolarização defendido por Freire (2006), quando indica que a educação deve estar adequada ao fim que persegue, possibilitando que os homens cheguem a ser sujeitos capazes de modificar o mundo, a cultura e a história. A educação precisa ser libertadora e não mais um meio de domesticação ou subjugação dos sujeitos. Sendo assim, é necessário não mais encarar os obstáculos como fontes de desânimo, mas sim como desafios que levam a investir em uma educação que contribua para a formação plena dos educandos, mesmo estes estando em situação de privação de liberdade (SOARES; VIANA, 2017).

Em relação à esperança, os participantes apontam que a maior expectativa que possuem é a saída do presídio e a possibilidade de recomeçar a vida de uma forma mais adequada e longe da criminalidade. Para que isto seja possível, indicam a importância da educação e dos professores e sua influência na esperança de uma oportunidade de se reinserirem sem retornar à criminalidade, como demonstra o relato abaixo:

A esperança é sair daqui, trabalhar e fazer um curso mais profundo, pra não retornar no crime. [...] é possível ver ética na educação dos presos, dos professores e os próprios agentes tratam a gente com educação. Bom e belo só trabalho que ajuda e o estudo acaba ensinando pro dia a dia e pro futuro.

\section{POLÊM!CA $\mid$ LABORE}

Polêmica - Revista Eletrônica da Uerj - Rua São Francisco Xavier, 524, $1^{\circ}$ andar bloco D, sl.1001 • Tels.: +55 21 2334-4088 / 4087 • http://www.e-publicacoes.uerj.br/index.php/polemica/index http://www.labore.uerj.br • laboreuerj@yahoo.com.br 
O participante destaca a ética na educação e nos profissionais que colaboram com a escola do presídio e o quanto os conhecimentos adquiridos nesse contexto servem como aprendizagem para o futuro que espera. Freire (2011) ressalta o papel importante do educador nesse processo, que deve buscar a certeza de que colabora com sua tarefa não apenas ao ensinar os conteúdos, mas também ao ensinar o seu educando a pensar certo. É possível analisar a teoria freiriana sendo aplicada quando os detentos dizem que os professores estão sempre os auxiliando a aprender e a buscar novas perspectivas, ou seja, educando também a forma de se pensar o mundo.

Dessa forma, se faz necessária a responsabilidade de refletir não somente sobre o espaço físico escolar da penitenciária, mas sobretudo construir um contexto de alegria e liberdade por aprender, ou seja, um ato educativo que consiga trabalhar contra a exclusão, superando as dificuldades e permitindo a esperança (FREIRE, 2011). Assim sendo, apesar dos obstáculos que os educandos do centro de detenção passam, percebe-se que escola se faz significativa na busca de mudanças e possibilidades de uma reinserção social. E como indica a teoria de Freire, o caminho é vivenciar uma educação que tenha como bases o amor, o respeito, a tolerância e a fé no ser humano, de modo que esta se torne crítica e reflexiva e modifique a realidade dos educandos.

\section{Considerações finais}

Nota-se que pensar a educação dentro de um contexto de privação de liberdade é uma tarefa complexa, mas necessária quando se julga está como uma forma de mudanças paradigmáticas do significado da escolarização nas vidas dos educandos atendidos. É possível observar que, por mais que a educação trabalhe e tente levar reflexões diferentes ao cotidiano prisional, ainda existem algumas barreiras, tais como a falta de recursos e, principalmente, de funcionários e educadores que valorizem a importância da oferta da escolarização nos sistemas.

Muitos dos educandos atendidos dentro do sistema penitenciário apresentam um histórico escolar deficitário, justificado principalmente pelas condições socioeconômicas. A maioria advém de famílias com baixo poder aquisitivo e alta vulnerabilidade social, que acarretam um afastamento mais prematuro do ambiente educacional. Dentro desse contexto, os detentos relatam que em dado momento da vida precisam escolher entre a escola e o trabalho,

\section{POLÊM!CA $\mid$ LABORE}

Polêmica - Revista Eletrônica da Uerj - Rua São Francisco Xavier, 524, $1^{\circ}$ andar bloco D, sl.1001 • Tels.: +55 21 2334-4088 / 4087 • http://www.e-publicacoes.uerj.br/index.php/polemica/index http://www.labore.uerj.br • laboreuerj@yahoo.com.br 
e sendo assim, abandonam o sistema educativo para ingressar em empregos, que muitas vezes também são desfavoráveis.

Quando estão em situação de privação de liberdade, estes sujeitos encontram a oportunidade de retomar sua escolarização dentro das escolas situadas nas penitenciárias. Neste momento de reinserção educativa, os detentos relatam encontrar novas formas de pensar o mundo. Considera-se que a educação dentro do sistema prisional trabalhe a um nível de consciência crítica, com educadores capazes de conduzir esses educandos a uma reflexão e descobertas de novos significados atribuídos ao aprendizado escolar.

Não houve, por parte dos participantes desta pesquisa, demonstrações de grandes aspectos negativos quanto à educação ofertada no presídio. A maioria dos detentos apontaram mais aspectos positivos quando questionados sobre a estrutura da escola na qual são atendidos durante a detenção. A maioria das reclamações se pautaram no sistema de matrículas, que são individuais e não por turma, fazendo com que em uma mesma sala, os educandos tenham aulas sobre conteúdos diferentes, o que, de acordo com alguns participantes, limita o trabalho do professor. Apesar deste fator, os mesmos participantes concordam que um outro sistema de turma não é viável no presídio devido à grande rotatividade dos presos nos períodos de aula.

Assim como em outros estudos, a pesquisa revela que esses educandos acreditam na educação e nas possibilidades que esta pode lhes oferecer quando estiverem fora da penitenciária. A grande parte dos sujeitos encarcerados, como já citado, não tiveram boas oportunidades em suas trajetórias de vida, principalmente a chance de instruir-se para assegurar um futuro melhor. Dessa maneira, o tempo consumido entre as grades pode e deve ser empregado para lhes garantir as oportunidades que nunca tiveram, por meio do estudo e de um trabalho que lhes possibilite uma nova visão.

\section{Referências}

AFONSO, L. P. V. Adaptação à Prisão: estudo das relações entre os processos de coping, "marcadores" de bem-estar e ajustamento psicológico. Dissertação (Mestrado em Psicologia). Universidade do Minho. Braga, 2012.

ARAÚJO, D. A. C. Educação Escolar no Sistema Penitenciário de Mato Grosso do Sul: um olhar sobre Paranaíba. Tese (Doutorado em Educação). UNICAMP. Campinas, SP, 2005.

BARDIN, L. Análise de conteúdo. São Paulo: Edições 70, 2011.

BAUER, C. Introdução crítica ao humanismo de Paulo Freire. São Paulo: Sundermann, 2008.

\section{POLÊM!CA $\mid$ LABORE}

Polêmica - Revista Eletrônica da Uerj - Rua São Francisco Xavier, 524, $1^{\circ}$ andar bloco D, sl.1001 • Tels.: +55 21 2334-4088 / 4087 • http://www.e-publicacoes.uerj.br/index.php/polemica/index http://www.labore.uerj.br • laboreuerj@yahoo.com.br 
BRASIL. Ministério da Justiça: Conselho Nacional de Política Criminal e Penitenciária. Resolução no 03, de 11 de março de 2009.

Presidência da República, Casa Civil. Decreto 7. 626, de 24 de novembro de 2011. Institui o Plano Nacional de Educação no âmbito do Sistema Prisional. Diário Oficial da União, Brasília, 25 de novembro de 2011.

Ministério da Justiça. Conselho Nacional de Justiça. Recomendação 44, de 26 de novembro de 2014. Dispõe sobre atividades educacionais complementares para fins de remição da pena pelo estudo e estabelece critérios para a admissão pela leitura. Diário Oficial da União, Brasília, 27 de novembro de 2014.

FREIRE, P. A importância do ato de ler: em três artigos que se completam. 23. ed. São Paulo: Autores Associados: Cortez, 1989.

Pedagogia da autonomia: saberes necessários à prática educativa. São Paulo: Paz e terra, 1996.

Conscientização: Teoria e prática da libertação: Uma introdução ao pensamento de Paulo Freire. 3. ed.. São Paulo: Centauro, 2006.

Educação como prática da liberdade. 34. ed. Rio de Janeiro: Paz e Terra, 2011.

Pedagogia do Oprimido. 60. ed. Rio de Janeiro: Paz e Terra, 2016.

HORA, D. M.; GOMES, P. R. Além da educação formal: complexidade e abrangência do ato de educar. Educação Prisional: o problema do ponto de vista do currículo. Salto para o Futuro. EJA e Educação Prisional. Boletim 06, 2007.

JULIÃO, E. F. O impacto da educação e do trabalho como programas de reinserção social na política de execução penal do Rio de Janeiro. Rev. Bras. Educ., Rio de Janeiro, v. 15, n. 45, p. 529-543, 2010.

LEITE, A. P. A Educação de Jovens e Adultos na Prisão. Ominia Humanas, online, v.2, n.2, p.60-69, 2009.

MÓL, M. J. L. A oferta de educação para adultos em situação de privação de liberdade na penitenciária Doutor Manuel Martins Lisboa Junior no município de Muriaé em Minas Gerais. Dissertação (Mestrado em Educação). Universidade Federal de Viçosa, Viçosa, MG, 2013.

OLIVEIRA. C. B. F. Para além das celas de aula: A educação escolar no contexto prisional à luz das representações dos presos: Um estudo de caso da penitenciária de Uberlândia/MG. Dissertação (Mestrado em Educação). Universidade Federal de Uberlândia, Uberlândia, MG, 2012.

ONOFRE, E. C.; JULIÃO, E. F. A Educação na Prisão como Política Pública: entre desafios e tarefas. Educação \& Realidade, vol.38, n.1, p.51-69, 2013.

PEREIRA, A. A educação-pedagogia no cárcere, no contexto da pedagogia social: definições conceituais e epistemológicas. Rev. Ed. Popular, Uberlândia, v. 10, p. 38-55, jan./dez. 2011.

A educação de jovens e adultos no sistema prisional brasileiro: o que dizem os planos estaduais de educação em prisões? Revista Tempos e Espaços em Educação, Lado direito, v. 11, n. 24, p. 245-252, jan. 2018.

PEREIRA, L. M. O Estado de Coisas Inconstitucional e a violação dos direitos humanos no sistema prisional brasileiro. RIDH, Bauru, v. 5, n. 1, p. 167-190, jan./jun., 2017.

RESENDE, N. V. Reencantar a Educação: a educação básica e a ressocialização dos presos. Dissertação (Mestrado em Desenvolvimento e Políticas Educativas) - Universidade Lusófona de Humanidades e Tecnologias, Lisboa 2012.

\section{POLÊM!CA $\mid$ LABORE}

Polêmica - Revista Eletrônica da Uerj - Rua São Francisco Xavier, 524, $1^{\circ}$ andar bloco D, sl.1001 • Tels.: +55 21 2334-4088 / 4087 • http://www.e-publicacoes.uerj.br/index.php/polemica/index http://www.labore.uerj.br • laboreuerj@yahoo.com.br 
SAUL, A. M.; SAUL, A. Contribuições de Paulo Freire para a formação de educadores: fundamentos e práticas de um paradigma contra-hegemônico. Educar em Revista, Curitiba, Brasil, n. 61, p. 19-35, jul./set. 2016.

SILVA, R.; MOREIRA, F. A. O projeto político-pedagógico para a educação em prisões. Em Aberto, Brasília, v. 24 , n. 86 , p. $89-103$, nov. 2011.

SOARES, C. P. G. Primeira escola prisional do Ceará: a avaliação da aprendizagem dos alunos privados de liberdade. 2015. 258 f. Dissertação (Mestrado em Educação) - Universidade Federal do Ceará, Programa de PósGraduação em Educação Brasileira, Universidade Federal do Ceará, Fortaleza, 2015.

SOARES, C. P. G.; VIANA, T. V. Por que ir à escola na prisão? Reflexões sobre os sentidos atribuídos pelos alunos privados de liberdade à educação. Interdisciplinary Scientific Journal, v. 4, n. 2, p. 131-146, apr./jun, 2017.

SOUSA, A. R. de. Pedagogia da despossuição: uma economia da produção de destituições radicais. In: JULIÃO, E. F. Educação para jovens e adultos em situação de privação de liberdade: questões, avanços e perspectivas, Jundiaí: Paco, 2013. p. 47-68.

TEIXERA, C. J. P. O papel da educação como programa de reinserção social para jovens e adultos privados de liberdade: perspectivas e avanços. Salto para o Futuro. EJA e Educação Prisional. Boletim 06, 2007.

UNESCO. Seminário Nacional pela Educação nas Prisões: significados e proposições. Ministério da Justiça e da Educação, Brasília, 2006.

Recebido em: 12/10/2017.

Aceito em: 30/09/2018.

\section{POLÊM!CA $\mid$ LABORE}

Polêmica - Revista Eletrônica da Uerj - Rua São Francisco Xavier, 524, $1^{\circ}$ andar bloco D, sl.1001 • Tels.: +55 21 2334-4088 / 4087 • http://www.e-publicacoes.uerj.br/index.php/polemica/index http://www.labore.uerj.br • laboreuerj@yahoo.com.br 


\section{Anexo I}

Roteiro da entrevista semiestruturada, adaptado do estudo de Araújo (2015).

1. Qual a maior dificuldade enfrentada na escola?

2. Estudava e/ou trabalhava quando foi detido?

3. Estuda na unidade prisional? Por quê?

4. Qual o seu interesse pelos conteúdos trabalhados em sala de aula?

5. Na sua opinião, a forma como são propostos os temas a serem trabalhados é boa ou ruim?

6. Você faz um aprofundamento dos assuntos trabalhados, após as aulas? Como?

7. São valorizadas as experiências dos alunos no decorrer das aulas?

8. Como é o relacionamento em sala de aula entre os presos e entre você e o(a) Professor(a)?

9. Existe uma colaboração entre os presos na sala de aula? De que forma?

10. São observados preconceitos na sala de aula? De que tipo?

11. O que representa a palavra esperança, para você, neste local?

12. É possível manter uma política ética e buscar o lado positivo das coisas ou pessoas neste ambiente? São realizadas atividades que valorizem essas posturas?

13. Em que momentos e locais é possível emitir opiniões sem repressões?

14. Qual a importância da educação neste local?

15. Você acha que a Educação faz alguma diferença na sua vida? Acrescenta algo? Explique.

16. Algum conhecimento adquirido em sala de aula fez você refletir sobre sua vida? Se sim, qual era o conteúdo? 17. Algum conteúdo trabalhado em sala de aula despertou seu interesse em determinado assunto ou campo de trabalho? Explique.

18. Você tem sugestões que possam contribuir para melhorar a educação no presídio?

19. Para você, esta unidade está auxiliando para seu retorno à sociedade?

20. O que pretende fazer após sair da prisão?

21. Vai continuar os estudos? Por quê?

\section{POLÊM!CA $\mid$ LABORE}

Polêmica - Revista Eletrônica da Uerj - Rua São Francisco Xavier, 524, $1^{\circ}$ andar bloco D, sl.1001 • Tels.: +55 21 2334-4088 / 4087 • http://www.e-publicacoes.uerj.br/index.php/polemica/index http://www.labore.uerj.br • laboreuerj@yahoo.com.br 